J. Lake Sci. (湖泊科学), 2012, 24(1): 43-50

http: //www. jlakes. org. E-mail : jlakes@niglas.ac.cn

(C) 2012 by Journal of Lake Sciences

\title{
二维水质模型在武汉东湖引水工程中的应用
}

\author{
余 成 ${ }^{1,2}$,任宪友 ${ }^{1 * *}$, 班 璇, 杜 耘 $^{1}$ \\ (1:中国科学院测量与地球物理研究所湖北省环境与灾害监测评估重点实验室,武汉 430077) \\ (2:中国科学院研究生院, 北京 100049)
}

摘 要: 以“大东湖生态水网”工程的实施为契机, 应用 MIKE21 软件对武汉东湖引水工程进行数值模拟. 利用东湖 2008 年 6 月和 7 月实测的水深、TN 和 TP 数据率定了模型参数 (床底摩擦力和涡粘系数), 并利用 2010 年 7 月实测数据建立水 动力学模型和对流扩散模型, 模拟了四种引水工况下模型运行 $35 \mathrm{~d}$ 之后东湖水体中 TN、TP 浓度分布情况, 并比较四种 工况的模拟结果. 结果表明:在设置两个引水口以及考虑风速影响的情况下,东湖水体中 TN、TP 浓度分布最均匀. 对“大 东湖生态水网”工程的实施具有一定的指导意义.

关键词: 东湖; 大东湖水网; MIKE21

\section{Application of two-dimensional water quality model in the project of the water diversion in East Lake, Wuhan}

\author{
YU Cheng ${ }^{1,2}$, REN Xianyou ${ }^{1}$, BAN Xuan $^{1} \&$ DU Yun ${ }^{1}$ \\ (1: Key Laboratory of Monitoring-Estimate for Environment and Disaster, Institute of Geodesy and Geophysics , Chinese Acad- \\ emy of Sciences, Wuhan 430077, P. R. China) \\ (2: Graduate University of Chinese Academy of Sciences, Beijing 100049, P. R. China)
}

\begin{abstract}
Based on the "Project of East Lake Hydrology Network", a numerical model of diversion project of East Lake was established using MIKE21. A calibration of the model parameters ( the bed resistance and the eddy viscosity) were performed by the water depth, the concentrations of total nitrogen and total phosphorus which were measured in East Lake in June and July in 2008. The hydrology model and the transport model are established by the measured value in East Lake in July, 2010. Four diversion conditions have been simulated. The distribution of total nitrogen and total phosphorus after 35 d' running have been established. Comparison of the simulated results of the four diversion conditions shows under the conditions of two inflows and considering both wind, the concentration, the distributions of total nitrogen and total phosphorus are the most uniform. This fining is important for the "Project of East Lake Hydrology Network".
\end{abstract}

Keywords: East Lake; Project of East Lake Hydrology Network; MIKE21

东湖是位于长江中下游的中型浅水湖泊, 是中国最大的城中湖. 由于人类活动的强力干预, 东湖经历了 剧烈的水生态环境变迁, 逐步由少受人类干扰的自然湖泊演变为富营养化的城市湖泊 ${ }^{[1]}$. 由于东湖相对封 闭、水体交换率低,大部分营养负荷滞留在水体中 ${ }^{[2]}$, 使水体富营养化严重 ${ }^{[3]}$. 学者们根据武汉东湖拥有毗 邻长江便于大量引水的便利条件, 初步研究了东湖与长江重新连通、恢复东湖水生态环境的问题 ${ }^{[4-5]}$.

2005 年武汉市按照武汉市水务局制订的《武汉市水生态系统保护与修复试点工作实施方案》, 实施大 东湖生态水网构建工程. 大东湖项目是以东湖为中心 , 以东沙湖水系、北湖水系为主要组成部分的江、湖、 港、渠组成的庞大水网, 将东湖、沙湖、杨春湖、严西湖、严东湖、北湖 6 个湖泊连通并与长江通连, 构建江湖 连通的生态水网湿地群,通过污染控制、水网连通和生态环境修复等措施, 将“大东湖”水网建设成为一个江

* 中国科学院知识创新工程重要方向性项目 (KZCX2-YW-141) 和湖北省自然科学基金项目 (2009CDB219) 联合资 助. $2011-01-30$ 收稿;2011-03-14 收修改稿. 余成,女, 1987 年生, 硕士研究生;E-mail: yc823@ whigg. ac. cn.

** 通信作者;E-mail:rxy@ whigg. ac. cn. 
湖连通的复合生态系统, 扭转大东湖区域水污染和生态环境破坏的趋势, 使东湖、沙湖等湖泊的水质逐渐好 转, 水质提升一个等级 ${ }^{[6]}$.

本文立足于 “大东湖生态水网工程”, 利用丹麦水动力学模型 MIKE $21 \mathrm{FM}$, 在综合考虑风场、人湖水质等 因素下, 模拟不同引水工况下东湖水体运动模式以及 TN 、TP 分布情况. MIKE $21 \mathrm{FM}$ 采用非结构网格, 能够处 理复杂的边界条件, MIKE 软件在国内外水环境研究领域已被广泛应用,王庆改等 ${ }^{[7]}$ 利用 MIKE21 进行来宾 电厂扩建工程温排水数值模拟研究, 王哲等 ${ }^{[8]}$ 应用 MIKE21 软件模拟了金仓湖流场并对金仓湖水质变化规 律进行预测与分析, 其数值模拟的科学性已得到世界公认 ${ }^{[9-11]}$. 通过对不同工况的模拟, 确定有利于东湖水 生态环境改善的引水工况, 为“大东湖生态水网工程” 提供一定的借鉴.

\section{1 研究区概况}

东湖 $\left(114^{\circ} 09^{\prime} \sim 114^{\circ} 39^{\prime} \mathrm{E}, 30^{\circ} 22^{\prime} \sim 30^{\circ} 41^{\prime} \mathrm{N}\right)$ 是城市浅水湖泊, 位于武汉市武昌东北部. 水域面积在水 位 $20.5 \mathrm{~m}$ 时为 $27.899 \mathrm{~km}^{2}$, 平均水深约 $2.21 \mathrm{~m}$, 最大水深 $4.75 \mathrm{~m}^{[12]}$, 是武汉市一个重要水源地和渔业基 地. 东湖原为敞水湖, 通过青山港与长江连接, 在修建了青山港武丰闸江湖分隔后, 东湖就由通江湖泊变为 封闭水体.

近 30 年来, 由于湖区周围人口密度不断增加、工农业生产、水产养殖以及旅游业的迅猛发展, 大量营养 物质进人东湖. 外源污染源源不断, 湖内污染日益加重, 导致浮游植物在数量上大幅增加, 群落结构上发生 明显变化, 以致水体浊度增大, 透明度降低, 水质下降, 富营养化日趋严重. 针对东湖的水生态环境, 武汉市 提出了“大东湖生态水网工程”, “引江济湖”, 将“死水”变“活水”,恢复东湖的水生态环境.

\section{2 模型简介}

MIKE21 是丹麦水环境研究所开发的一个二维水质模拟软件, 适用于河口、海岸、湖泊, 其拥有四种网格形 式, 能拟合复杂的边界条件. 东湖边界条件复杂, 因此选择 MIKE21 对东湖引水工程进行模拟. 本文选择了 MIKE21 的两个模块, 分别是水动力学模块和对流扩散模块. 水动力学模块能模拟由于外界条件变化引起的水 体水位和流场的变化, 是 MIKE21 中其它模块的基础. 对流扩散模块能模拟在不同外界条件影响下湖泊中营养 物质的扩散、迁移过程. 因此本文选择这两个模块分别模拟不同工况下的东湖水动力学和营养物质扩散状况.

\section{1 水动力学模块}

水动力学模块模拟一个垂直均匀层的二维流场的不稳定流动. 公式 (1 3) 是垂直上的质量和动量的守 恒, 描述了流场和水位的变化.

$$
\begin{gathered}
\frac{\partial}{\partial t}(h c)+\frac{\partial}{\partial x}(u h c)+\frac{\partial}{\partial x}(v h c)=\frac{\partial}{\partial x}\left(h \cdot D_{x} \cdot \frac{\partial c}{\partial x}\right)+\frac{\partial}{\partial y}\left(h \cdot D_{y} \frac{\partial c}{\partial y}\right)-F \cdot h \cdot c+S \\
\frac{\partial p}{\partial t}+\frac{\partial}{\partial x}\left(\frac{p^{2}}{h}\right)+\frac{\partial}{\partial y}\left(\frac{p q}{h}\right)+g h \frac{\partial \zeta}{\partial x}+\frac{g p \sqrt{p^{2}+q^{2}}}{C^{2} \cdot h^{2}}-\frac{1}{\rho_{w}}\left[\frac{\partial}{\partial x}\left(h \tau_{x x}\right)+\frac{\partial}{\partial y}\left(h \tau_{x y}\right)\right]-\Omega_{q}-f V V_{x}+\frac{h}{\rho_{w}} \frac{\partial}{\partial x}\left(p_{a}\right)=0 \\
\frac{\partial q}{\partial t}+\frac{\partial}{\partial y}\left(\frac{q^{2}}{h}\right)+\frac{\partial}{\partial x}\left(\frac{p q}{h}\right)+g h \frac{\partial \zeta}{\partial y}+\frac{g q \sqrt{p^{2}+q^{2}}}{C^{2} \cdot h^{2}}-\frac{1}{\rho_{w}}\left[\frac{\partial}{\partial y}\left(h \tau_{y y}\right)+\frac{\partial}{\partial x}\left(h \tau_{x y}\right)\right]+\Omega_{p}-f V V_{y}+\frac{h}{\rho_{w}} \frac{\partial}{\partial x y}\left(p_{a}\right)=0
\end{gathered}
$$

式中, $h(x, y, t)$ 为水深 $(\mathrm{m}) ; d(x, y, t)$ 为随时间变化的水深 $(\mathrm{m}) ; \zeta(x, y, t)$ 为水位 $(\mathrm{m}) ; p, q(x, y, t)$ 为 $x$ 和 $y$ 方向上的流量密度 $\left(\mathrm{m}^{3} /(\mathrm{s} \cdot \mathrm{m})\right)=(u h, v h), u$ 和 $v$ 为 $x$ 和 $y$ 方向上的平均流速 $(\mathrm{m} / \mathrm{s}) ; C(x, y)$ 为谢才 阻力 $\left(\mathrm{m}^{\frac{1}{2}} / \mathrm{s}\right) ; g$ 为重力加速度 $\left(\mathrm{m} / \mathrm{s}^{2}\right) ; f(V)$ 为风摩擦系数; $V, V_{x}, V_{y}(x, y, t)$ 为风速以及 $x, y$ 方向上的分 速度 $(\mathrm{m} / \mathrm{s}) ; \Omega(x, y)$ 为科里奥力参数 $\left(\mathrm{s}^{-1}\right) ; p_{\mathrm{a}}(x, y, t)$ 为大气压力 $\left(\mathrm{kg} /\left(\mathrm{m} \cdot \mathrm{s}^{2}\right)\right) ; \rho_{\mathrm{w}}$ 为水密度 $\left(\mathrm{kg} / \mathrm{m}^{3}\right) ;$ $x, y$ 为空间坐标 $(\mathrm{m}) ; t$ 为时间 $(\mathrm{s}) ; \tau_{x x}, \tau_{x y}, \tau_{y y}$ 为有效剪应力的组成部分.

\section{2 对流扩散模块}

对流扩散模块模拟了湖泊、港口和沿海区域可溶解物质的扩散过程. 方程式为:

$$
\frac{\partial}{\partial t}(h c)+\frac{\partial}{\partial x}(u h c)+\frac{\partial}{\partial x}(v h c)=\frac{\partial}{\partial x}\left(h \cdot D_{x} \cdot \frac{\partial c}{\partial x}\right)+\frac{\partial}{\partial y}\left(h \cdot D_{y} \frac{\partial c}{\partial y}\right)-F \cdot h \cdot c+S
$$


式中, $c$ 为复合浓度 (常量) ; $u, v$ 为 $x, y$ 方向上的水平速度 $(\mathrm{m} / \mathrm{s}) ; h$ 为水深 $(\mathrm{m}) ; D_{x}, D_{y}$ 为 $x, y$ 方向上的扩 散系数 $\left(\mathrm{m}^{2} / \mathrm{s}\right) ; F$ 为线性衰减系数 $\left(\mathrm{s}^{-1}\right) ; S=Q_{s},\left(c_{s}-c\right)$, 其中 $Q_{s}$ 为源汇项流量 $\left(\mathrm{m}^{3} /\left(\mathrm{s} \cdot \mathrm{m}^{2}\right)\right), c_{s}$ 为源汇项 处化合物的浓度; $u, v, h$ 由水动力学模块提供.

\section{3 计算方法}

运用湖泊水动力学的理论和方法, 采用非结构网格, 以湖泊水动力学模型为基础, 建立东湖二维水质 模型, 利用有限差分的数值格式求解模型的连续方程、动量方程和污染物输移扩散方程, 得到湖水运动的 流场和污染物浓度场, 分析不同引水工况对东湖水质的影响, 确定有利于东湖水生态环境改善的引水 工况.

\section{3 二维东湖水质模型建立}

\section{1 数据的获取}

2008 年和 2010 年,分别在东湖 12 个样点进行采样 （图 1), 通过现场测定和实验室分析,得到东湖水深、总氮 $(\mathrm{TN})$ 、总磷 $(\mathrm{TP})$ 数据. $\mathrm{TN}$ 测定采用过硫酸钾氧化紫外分 光光度法, $\mathrm{TP}$ 测定采用钼锑抗分光光度法 ${ }^{[13]}$.

以东湖 2008 年 6 月的水深、TN、TP 数据作为初始条 件, 以 2008 年 7 月数据作为验证数据来率定模型. 以 2010 年 7 月东湖水深、 $\mathrm{TN} 、 \mathrm{TP}$ 数据作为初始数据建立模型并 进行模拟.

\section{2 地形文件的建立}

在 ArcGIS 里将东湖边界矢量化,然后转成. xyz 文件, 通过 MIKE21FM 生成东湖边界, 在 MIKE21 中此边界默认 为陆地, 并且可以设置为不参与插值, 这种设置结果能使 地形的插值不受到湖泊岸线的影响. 然后利用网格生成器

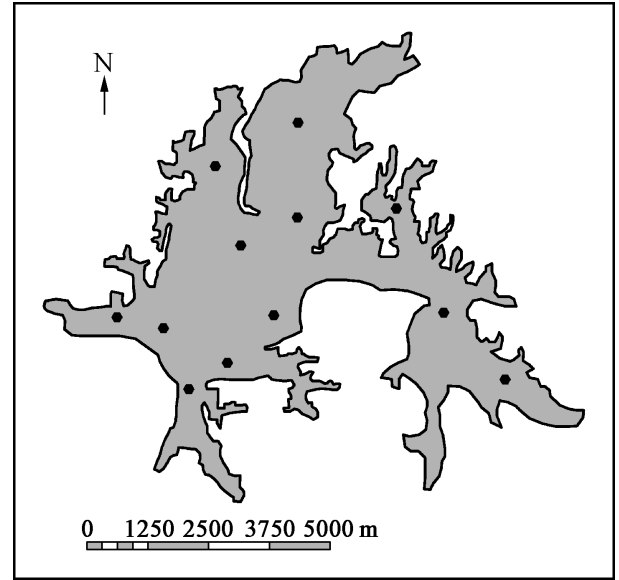

图 1 东湖采样点分布图

Fig. 1 Location of sampling sites in East Lake 生成东湖区域内部地形的网格,本文在计算中选择非结构 网格,能较好地拟合东湖复杂的边界 (图 2a). 模型计算网格由 5211 个三角形网格组成,计算节点 2978 个. 导人东湖 2008 年 12 个采样点的水深数据, 进行插值, 采用自然单元法中的自然邻接点插值方法 (natural neighbour), 得到东湖地形文件(图 2b).
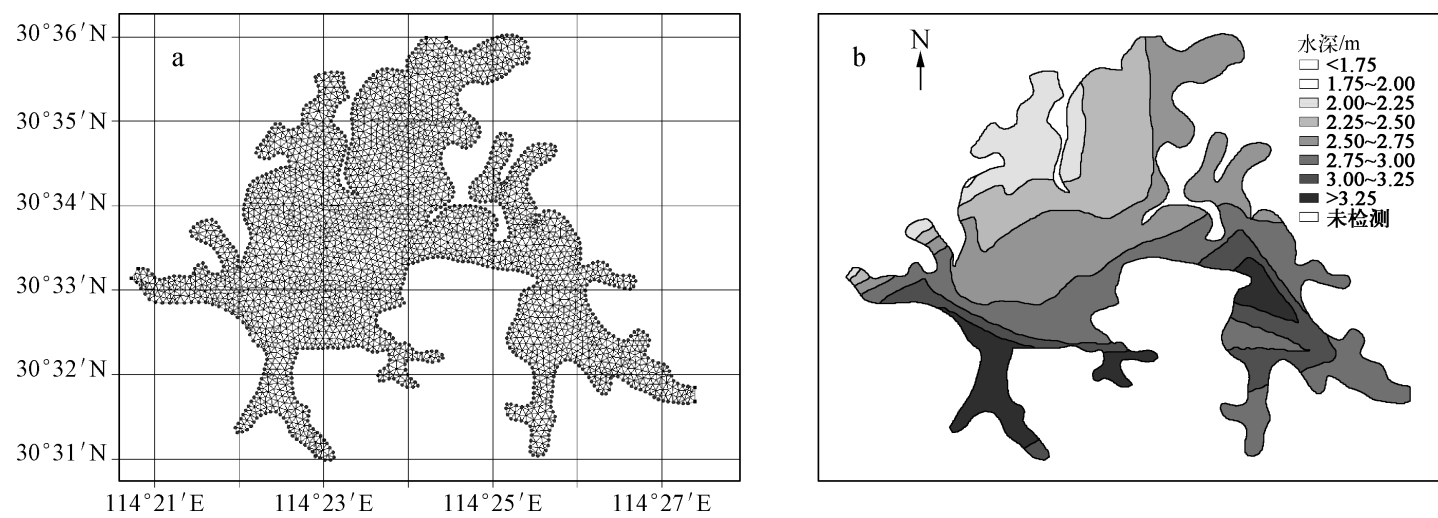

图 2 东湖计算网格 (a) 和水下地形 (b)

Fig. 2 Computing grids(a) and terrain(b) of East Lake

\section{3 模型验证}

以 2008 年 6 月东湖的实测数据为初始条件, 由于缺少实测的时间序列的风场数据, 采用 6 月的多年平 

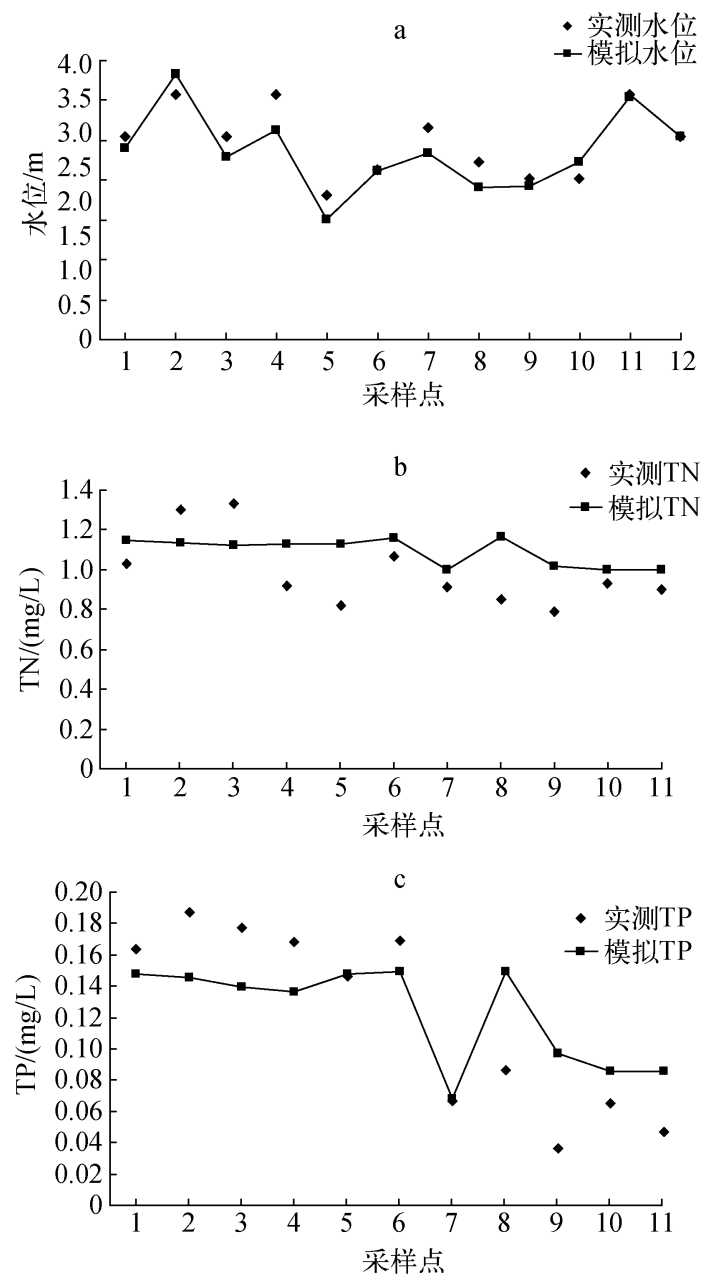

图 3 东湖水位 $(\mathrm{a}) 、 \mathrm{TN}(\mathrm{b})$ 和 $\mathrm{TP}(\mathrm{c})$ 率定结果

Fig. 3 The calibration results of water level(a), $\mathrm{TN}(\mathrm{b})$ and $\mathrm{TP}(\mathrm{c})$ of East Lake

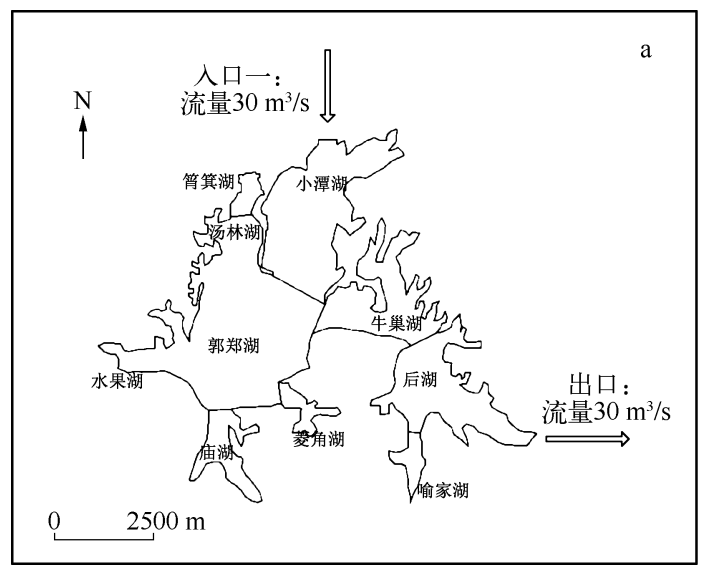

均风速 $3.5 \mathrm{~m} / \mathrm{s}$, 主导风向为东风, 以 2008 年 7 月 数据作为验证数据. 根据 2008 年 7 月实测的东湖 12 个样点的水位数据对水动力学模型进行率定, 平 均误差为 $5.3 \%$ (图 3a) ; 根据 $\mathrm{TN} 、 \mathrm{TP}$ 数据对对流 扩散模型进行率定, 平均误差分别为 $18.5 \%$ 和 27.3\% (图 3b, 图 3c). 水位、 $\mathrm{TN}$ 和 $\mathrm{TP}$ 的率定结果 可以接受. 模型率定结果: 床底摩擦力 (Manning number) 为 $45 \mathrm{~m}^{1 / 3} / \mathrm{s}$, 涡粘系数 (Smagorinsky formulation) 为 0.28 (图 3 ).

\section{4 模拟工况}

根据武汉市水务局制定的《武汉市水生态系统 保护与修复试点工作实施方案》, 设定两个引水口 设置, 为了研究自然条件, 如风速对水动力学和污 染物浓度扩散的影响, 在两个引水口设置中又分别 设置了不考虑风场和考虑风场的情况, 并从长江引 水, 根据卓海华等 ${ }^{[14]} 2008$ 年监测的长江武汉段的 数据, 引水口处水质为 II 类, 同时根据湖北省环境 监测中心站公布的湖北省武汉市城市圈地表水环 境质量月报 ${ }^{[15]}, 2010$ 年长江武汉段水质为 II 类. 根 据《地表水环境质量标准》( GB3838-2002) 中的 II 类标准, 将引水中 $\mathrm{TN}$ 浓度设定为 $0.5 \mathrm{mg} / \mathrm{L}, \mathrm{TP}$ 浓 度设定为 $0.05 \mathrm{mg} / \mathrm{L}$. 四种工况设置为:工况一, 设 定了一个引水口和一个出水口, 流量都为 $30 \mathrm{~m}^{3} / \mathrm{s}$ (图 4a); 工况二, 设定了两个引水口和一个出水 口, 引水口一的流量为 $30 \mathrm{~m}^{3} / \mathrm{s}$, 引水口二的流量为 $10 \mathrm{~m}^{3} / \mathrm{s}$, 出水口的流量则为 $40 \mathrm{~m}^{3} / \mathrm{s}$ (图 $4 \mathrm{~b}$ ); 工况 三, 在工况一的基础上考虑风速的影响, 风速大小 设定为 $3.5 \mathrm{~m} / \mathrm{s}$, 风向为东风; 工况四, 在工况二的 基础上考虑风速的影响, 风速大小设定为 $3.5 \mathrm{~m} / \mathrm{s}$, 风向为东风.

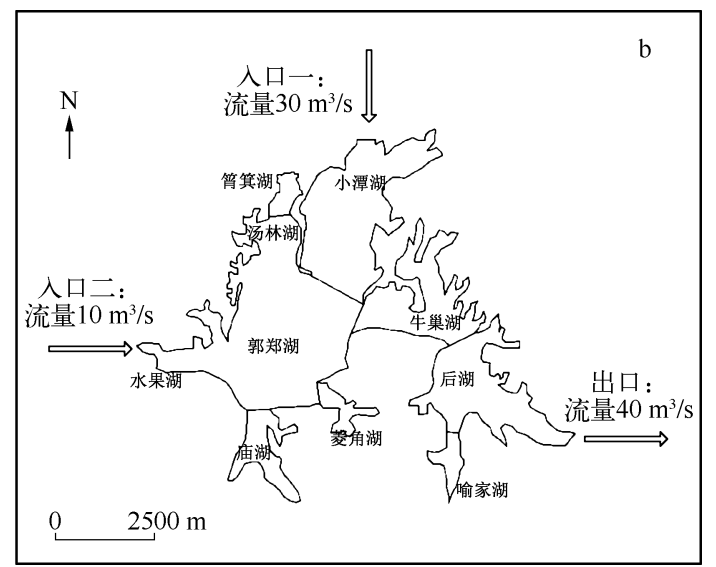

图 4 工况一 ( a ) 和工况二(b)引水图

Fig. 4 The diversion gates under the first scenario(a) and the second scenario(b) 


\section{5 边界条件}

在对流扩散模块中有三个边界条件, 人口一处流量为 $30 \mathrm{~m}^{3} / \mathrm{s}$, 人流水质 $\mathrm{TN}$ 浓度为 $0.5 \mathrm{mg} / \mathrm{L}, \mathrm{TP}$ 浓度 为 $0.05 \mathrm{mg} / \mathrm{L}$; 人口二处流量为 $10 \mathrm{~m}^{3} / \mathrm{s}$, 人流水质 $\mathrm{TN}$ 浓度为 $0.5 \mathrm{mg} / \mathrm{L}$, TP 浓度为 $0.05 \mathrm{mg} / \mathrm{L}$; 出口流量分别 为 $30 、 40 \mathrm{~m}^{3} / \mathrm{s}$.

\section{4 结果与分析}

根据东湖 2010 年 7 月实测数据进行模拟, $35 \mathrm{~d}$ 之后水动力学和对流扩散模型计算结果趋于稳定,得到 $35 \mathrm{~d}$ 之后的氮、磷分布情况. 对 7 月份实测的 TN、TP 浓度值采用自然邻接点插值法 (natural neibour) 进行插 值,2010 年 7 月 TN 和 TP 的初始浓度分布结果见图 5.
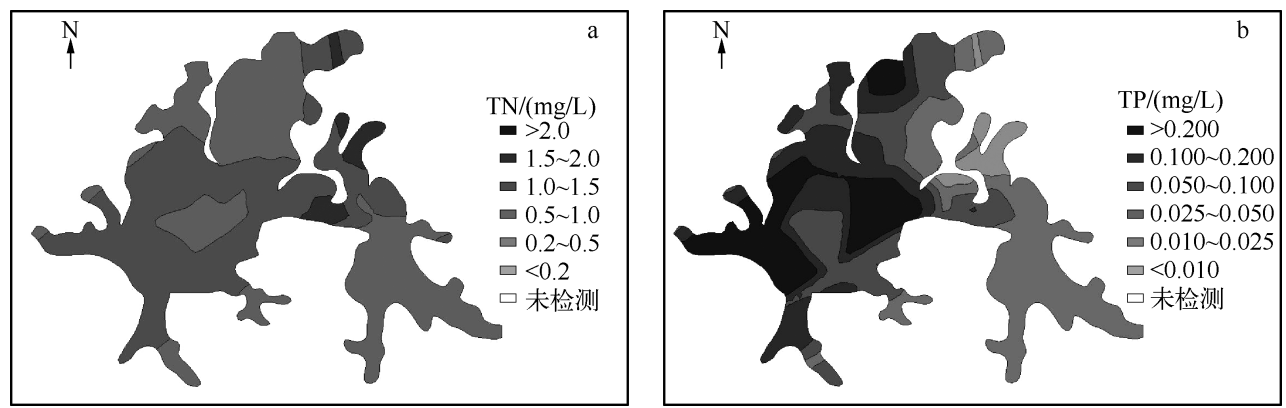

图 5 东湖 2010 年 7 月 $\mathrm{TN}(\mathrm{a}) 、 \mathrm{TP}(\mathrm{b})$ 初始浓度分布

Fig. 5 The initial distribution of total nitrogen(a) and total phosphorus( b) in East Lake in July, 2010

\section{1 模拟结果}

与初始浓度 (图 5a) 相比, 四种工况下 TN 浓度均有所降低. 四种工况下后湖和喻家湖 TN 浓度值最低, 工 况一下 TN 浓度范围 $1 \sim 1.5 \mathrm{mg} / \mathrm{L}$ 占的面积最大, 工况四条件下最小, 且工况四下东湖 TN 分布最均匀(图 6).
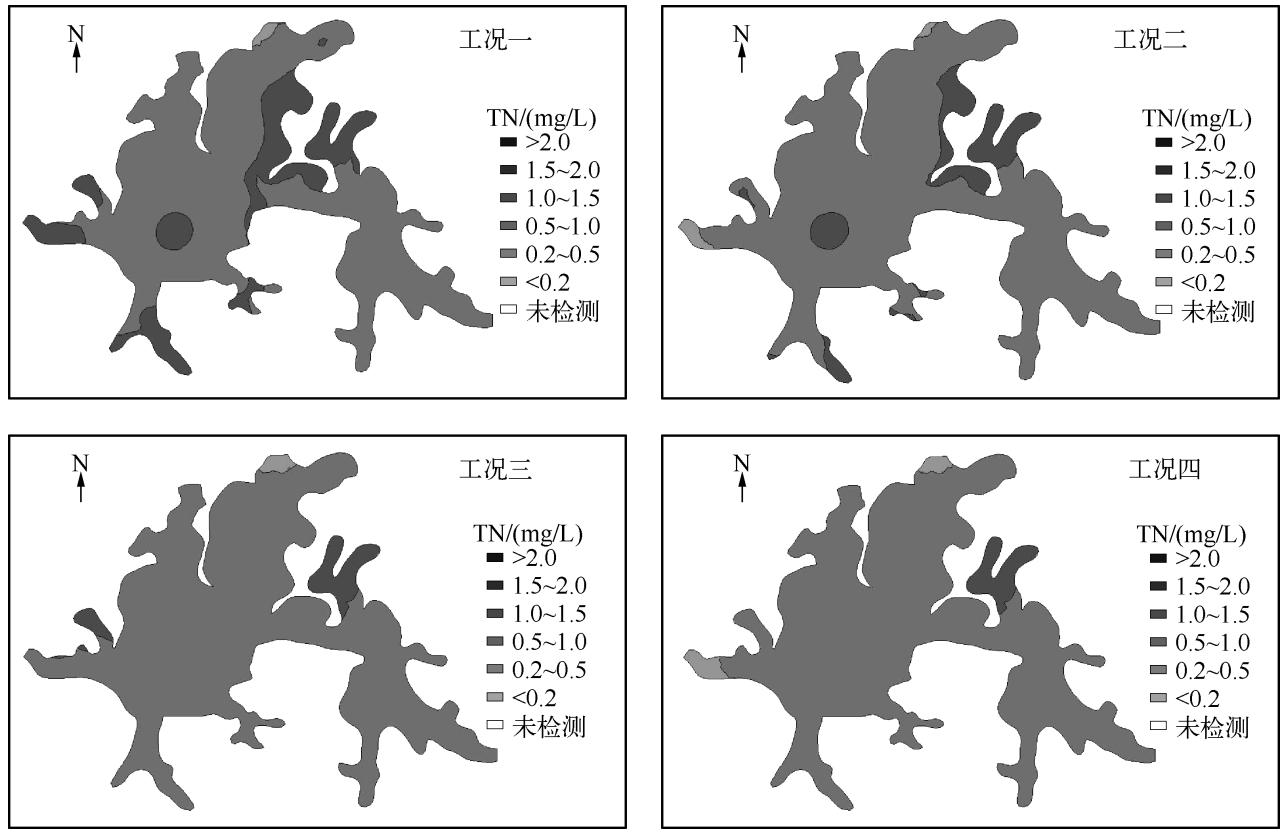

图 6 四种工况下模拟 $35 \mathrm{~d}$ 后 $\mathrm{TN}$ 空间分布

Fig. 6 The spatial distribution of total nitrogen under four scenarios after simulating $35 \mathrm{~d}$ 
与初始浓度 (图 5b) 相比, 四种工况下 TP 浓度均有所降低, 后湖和喻家湖 TP 浓度分布一致, 工况一下 $\mathrm{TP}$ 浓度范围 $0.1 \sim 0.2 \mathrm{mg} / \mathrm{L}$ 所占面积最大, 且主要位于庙湖、水果湖和郭郑湖的东北部. 工况四条件下, 东 湖 TP 浓度范围 $0.1 \sim 0.2 \mathrm{mg} / \mathrm{L}$ 所占面积最小, 且分布最均匀(图 7 ).

因此, 设置两个引水口并考虑风影响的情况下东湖水体中 TN 和 TP 浓度分布最均匀(图 6, 图 7).
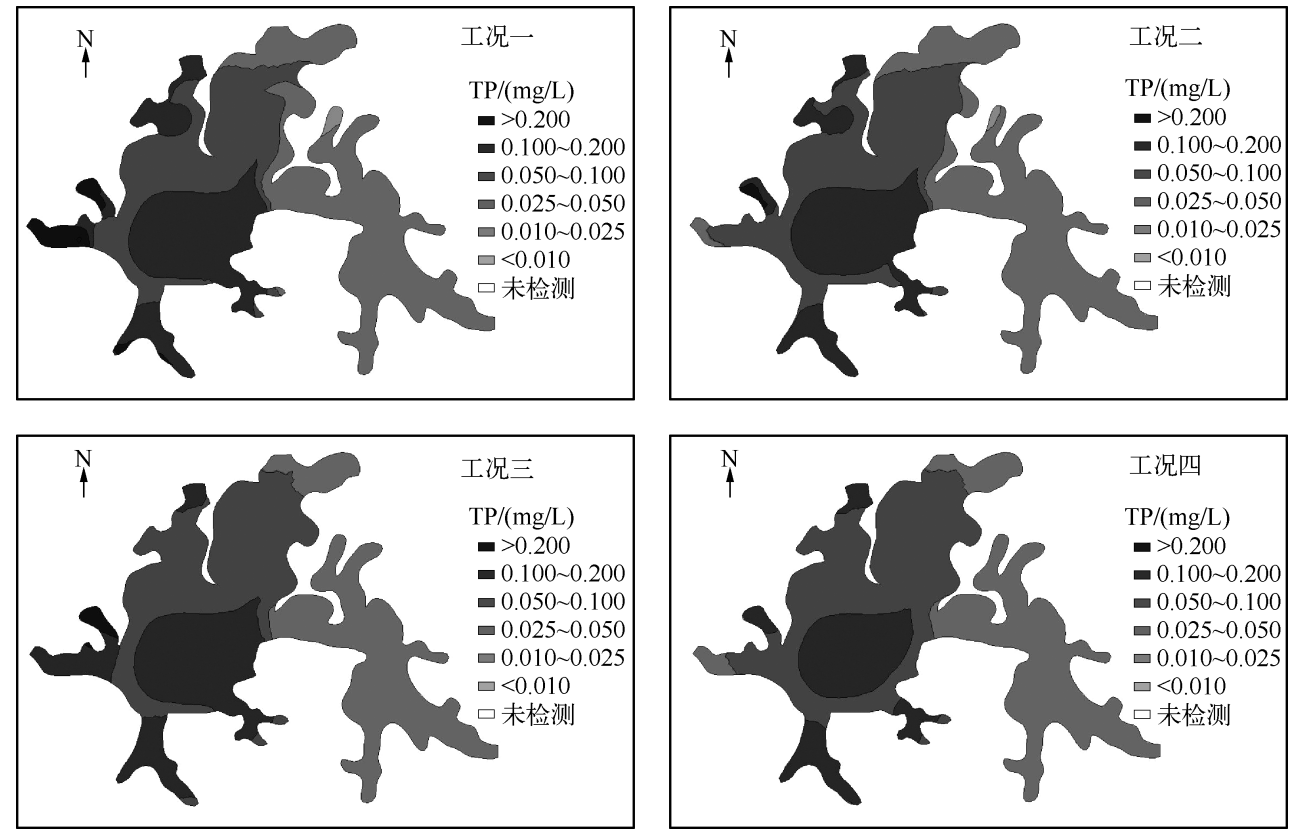

图 7 四种工况模拟 $35 \mathrm{~d}$ 后 TP 空间分布

Fig. 7 The spatial distribution of total phosphorus under four scenarios after simulating $35 \mathrm{~d}$

\section{2 四种工况模拟结果比较}

分别提取四种工况下模拟 $35 \mathrm{~d}$ 后的东湖 12 个样点的 TN TP 值. 对模拟结果进行了三组对比, 分别是工 况一和工况二与初始浓度的对比 (图 8), 工况一和工况三与初始浓度的对比 (图 9) 以及工况二和工况四与 初始浓度的对比 (图 10). 其中四种工况与初始浓度相比较的差异值公式为:

$$
\begin{aligned}
\Delta x_{i} & =\sum\left(x_{i j}-x_{0 j}\right)(i=1,2,3,4 ; j=1,2 \cdots 12) \\
\Delta y_{i} & =\sum\left(y_{i j}-y_{0 j}\right)(i=1,2,3,4 ; j=1,2 \cdots 12)
\end{aligned}
$$

式中, $x$ 代表 TN, $y$ 代表 TP. 对比结果表明, 差异值 $1 、 2 、 3 、 4$ 均为负值, 表明在四种工况下, TN、TP 浓度均有 所降低 (表 1). 其中差异值 2 最大, 差异值 4 次之, 因此在工况二下, 即设置两个引水口, 不考虑风速的影响, 评 价浓度降低的最多. 差异值 2 和 4 均大于差异值 1 和 3 , 说明在两个引水口比一个引水口情况下东湖水质 $\mathrm{TN}$ 和 TP 浓度降低得多. 结果表明,增加一个引水口能增加东湖水体中污染物的扩散速度.

表 1 四种工况下 TN、TP 模拟值与初始浓度值对比结果 *

Tab. 1 Comparing results of simulation and initial concentrations of TN and TP under four scenarios

\begin{tabular}{ccccc}
\hline & 差异值 1 & 差异值 2 & 差异值 3 & 差异值 4 \\
\hline $\mathrm{TN}$ & -0.21 & -0.26 & -0.20 & -0.24 \\
$\mathrm{TP}$ & -0.065 & -0.081 & -0.070 & -0.078 \\
\hline
\end{tabular}

* 差异值 $1 、 2 、 3 、 4$ 分别为工况一、工况二、工况三和工况四的模拟值与初始浓度的比较, 负值表示浓度降低. 

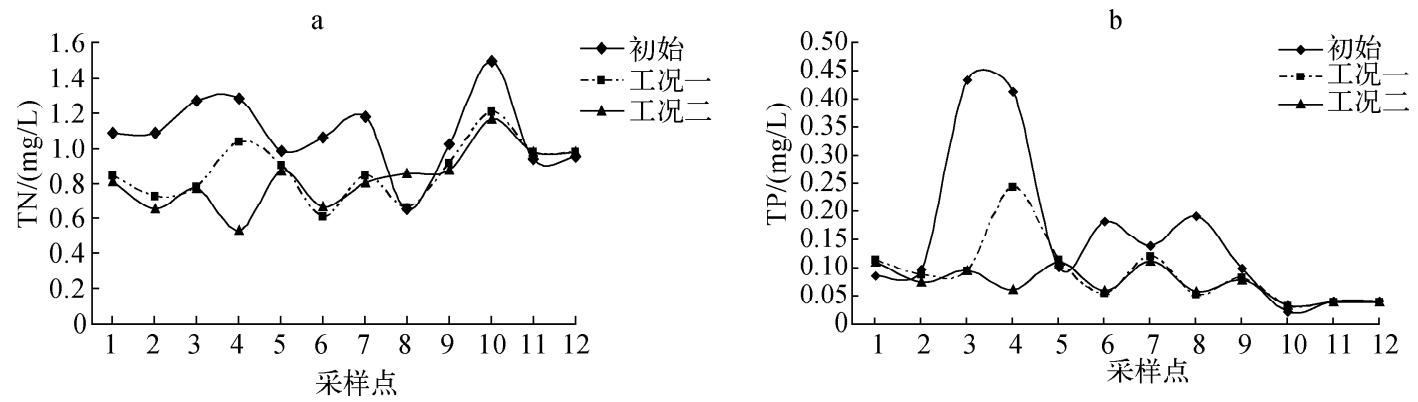

图 8 工况一和工况二条件下模拟 $35 \mathrm{~d}$ 后 $\mathrm{TN}(\mathrm{a}) 、 \mathrm{TP}(\mathrm{b})$ 浓度

Fig. 8 Concentrations of total nitrogen(a) and total phosphorus(b) under the first and the second scenarios after simulating $35 \mathrm{~d}$
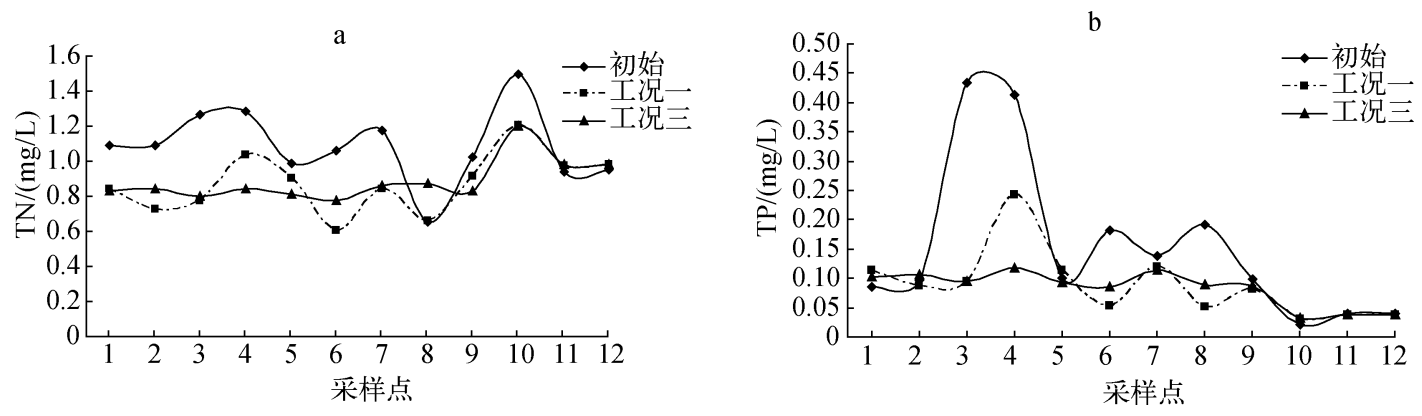

图 9 工况一和工况三模拟 $35 \mathrm{~d}$ 后 $\mathrm{TN}(\mathrm{a}) 、 \mathrm{TP}(\mathrm{b})$ 浓度

Fig. 9 Concentrations of total nitrogen(a) and total phosphorus(b) under the first and the third scenarios after simulating $35 \mathrm{~d}$
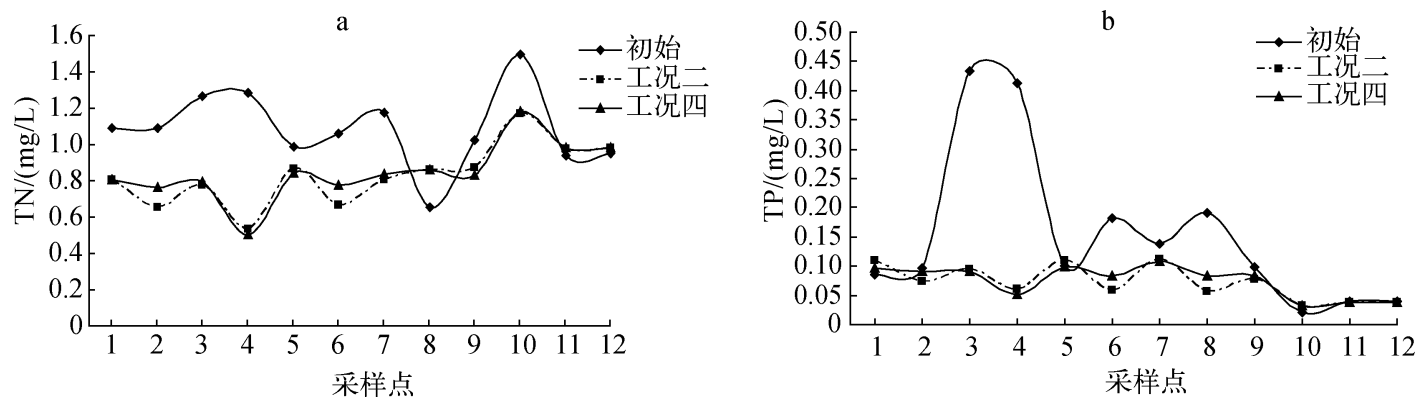

图 10 工况二和工况四模拟 $35 \mathrm{~d}$ 后 $\mathrm{TN}(\mathrm{a})$ 、 $\mathrm{TP}(\mathrm{b})$ 浓度

Fig. 10 Concentrations of total nitrogen(a) and total phosphorus (b) under the second and the fourth scenarios after simulating $35 \mathrm{~d}$

\section{5 结论与讨论}

本文实现了利用 MIKE21FM 对 “大东湖生态水网”引水工程的数值模拟, 建立以非结构网格为基础的地 形文件, 率定模型参数 (床底摩擦力和浴粘系数), 建立水动力学模型和对流扩散模型, 模拟四种引水工况条 件下引水过程对东湖水质的影响. 
模拟结果表明,四种引水工况均可以降低东湖水体中 TN、TP 的浓度值, TN 和 TP 浓度空间分布表明, 在工况四下水质分布最均匀, 模拟效果最好. 通过选取样点进行差异值比较得出, 工况二下 TN 和 TP 浓度值 降低的最多. 出现此现象的原因可能是选取样点本身存在一定的误差, 部分样点位于湖汉处, 引水过程和风 对其污染物扩散的影响小. 同时工况二和工况四的差异值相差很小. 工况二和工况四的差异值都大于工况 一和工况三, 说明增加引水口可以增加东湖水体中污染物扩散速度.

致谢: 采样和实验测定过程中, 实验室冯奇博士、李晓冬、赵国松、刘䜭、严翼、李远征等给予了很大的帮助. 在此,向他们表示衷心的感谢.

\section{6 参考文献}

[ 1 ] Xie P, Liu J. Practical success of biomanipulation using filter-feeding fish to control cyanobacteria blooms. The Scientific World, 2001, (1) : 337-356.

[ 2 ] Tang H, Xie P. Budgets and dynamics of nitrogen and phosphorus in a shallow, hypereutrophic lake in China. Journal of Freshwater Ecology, 2000, 15(4) : 505-514.

[3] 杨 洪, 易朝路, 谢 平等. 人类活动在武汉东湖沉积物中的记录. 中国环境科学, 2004, 24(3): 261-264.

[ 4] 周 俊, 王焰新, 蔡鹤生. 构建“长江-东湖-长江” 水循环及其在东湖污染治理中的意义. 武汉大学学报: 工学 版, 2002, 35(4) : 64-67.

[ 5] 金伯欣, 李新民, 刘苏峡. 武汉东湖引江灌湖控制水质可行性的初步研究. 华中师范大学学报: 自然科学版, 1991,25 ( 1 ) : 125-128.

[6] 严江涌, 黎南关. 武汉市大东湖水网连通治理工程浅析. 人民长江, 2010, 41(11): 82-84.

[ 7 ] 王庆改, 戴文楠, 赵晓宏等. 基于 Mike21 FM 的来宾电厂扩建工程温排水数值模拟研究. 环境科学研究, 2009, 22 (3) :332-336.

[8] 王 哲, 刘 凌, 宋兰兰. Mike21 在人工湖生态设计中的应用. 水电能源科学, 2008, 26(5): 124-127.

[9] 谭炳卿, 张国平. 淮河流域水质管理模型. 水资源保护, 2001, (3) : 15-18.

[10 ] Keller V. Risk assessment of “down-the drain” chemicals : search for a suitable model. Science of the Total Environment, $2006, \mathbf{3 6 0}(1 / 2 / 3): 305-318$.

[11] 龚春生, 姚 琪, 赵棣华等. 浅水湖泊平面二维水流-水质一底泥污染模型研究. 水科学进展, 2006, 17 (4): 496-501.

[12] 刘建康. 东湖生态学研究 (一). 北京: 科学出版社, 1990: 379-387.

[13] 国家环境保护总局《水和废水监测分析方法》编委会. 水和废水监测分析方法. 北京: 中国环境科学出版 社, 2002.

[14] 卓海华, 朱志勋, 兰 静等. 武汉江段水质综合监测与评价. 人民长江, 2008, 39(27): 134-136.

[15] 湖北省环境监测中心站 (www. hbemc. com. cn). 